\title{
Slaapstoornissen en epilepsie: is het van belang?
}

Het is bekend dat mensen met epilepsie vaker slaapproblemen hebben dan mensen zonder epilepsie. Daarnaast kunnen nachtelijke aanvalsgewijze slaapstoornissen moeilijk te onderscheiden zijn van epileptische aanvallen. Ook kan behandeling van epilepsie invloed hebben op de slaap. Het is van belang om deze complexe relatie tussen epilepsie en slaap te onderkennen bij mensen met epilepsie.

\section{Slaap versus epilepsie}

De invloed van slaap op epilepsie is divers. Zo wordt tijdens zogenaamde NREM (non-rapid eye movement)-slaap een toename gezien van epileptische ontladingen, terwijl er tijdens de REM (rapid eye movement)-slaap juist vaak een afname te zien is. Bij sommige soorten epilepsie komen epileptische aanvallen dan ook vaker voor tijdens NREMslaap. Een van de opmerkelijkste voorbeelden is de Electrical Status Epilepticus during Sleep (ESES), waarbij tijdens NREM-slaap continu (meer dan $85 \%$ van de tijd) epileptische ontladingen worden gezien (Malow, 2007). Epileptische aanvallen in het kader van focale epilepsie vanuit de frontale en temporale hersenkwabben treden ook tijdens de NREM-slaap op. Bij andere vormen van epilepsie treden de aanvallen daarentegen juist met name rond het tijdstip van ontwaken of in de vroege ochtend op, zoals bij juveniele myoclonus epilepsie en focale epilepsie met centro-temporale pieken. Een chronisch tekort aan slaap, ook wel slaapinsufficiëntie genoemd, kan een toename geven van het aantal epileptische aanvallen.

Epilepsie en het hebben van (nachtelijke) epileptische aanvallen kan ook een veelal nadelig effect hebben op de slaaparchitectuur en daardoor op de slaapkwaliteit (Bazil, 2003). Zo is de slaap vaker gefragmenteerd, waarbij er veel wisselingen ontstaan tussen de diverse slaapstadia en zijn er vaker momenten van wakker worden. Ook kan de hoeveelheid REM-slaap afnemen en verschuiven naar een later tijdstip in de nacht. Dit negatieve effect op de REM-slaap wordt overigens niet alleen gezien indien er nachtelijke epileptische aanvallen zijn, maar ook bij aanvallen overdag.

\section{Slaapstoornissen bij epilepsie}

Bij mensen met epilepsie komen klachten als slaperigheid overdag, angststoornissen en depressieve klachten veel voor. Dergelijke klachten kunnen ook veroorzaakt worden door slaapstoornissen en kunnen een enorme impact hebben op de kwaliteit van leven. Slaapstoornissen komen namelijk twee tot driemaal vaker voor bij mensen met epilepsie in vergelijking met gezonde mensen. Dit geldt zowel voor kinderen als volwassenen (van Golde et al., 20II; Gutter et al., 2019).

Het hebben van een slaapstoornis heeft ook invloed op de epilepsie: zowel de frequentie als de ernst van de aanvallen kunnen toenemen. Hierdoor kan de slaapstoornis ook weer verergeren. Klachten van slaperigheid overdag kunnen veroorzaakt worden door het gebruik van anti-epileptica, het voorkomen van (nachtelijke) aanvallen, maar ook door slaapstoornissen, denk aan slaap-apneu of het rusteloze benen-syndroom.

Insomnie, ofwel slapeloosheid, uit zich door het niet goed in slaap kunnen vallen, het niet goed doorslapen of te vroeg wakker worden. Dit kan veroorzaakt worden door slaapfragmentatie door epileptische aanvallen of door het gebruik van anti-epileptica, maar ook door bijvoorbeeld gedragsveranderingen als gevolg van de diagnose en/of door een toename van depressieve klachten en angstklachten. Slaapgerichte gedragstherapie en cognitieve gedragstherapie gericht op de slapeloosheid zouden hiervoor een goede behandeloptie kunnen zijn, ook als de epilepsie hierbij een rol speelt (Latreille, 2018).

Slaap-apneu is een veel voorkomende slaapstoornis bij mensen met epilepsie. Er wordt gesproken van een slaapapneu-syndroom als dit klachten geeft, de meest typische zijnde slaperigheid overdag. Deze aandoening komt veel voor bij mannen, bij obesitas en als gevolg van anatomische afwijkingen zoals craniofaciale afwijkingen. Met name bij refractaire epilepsie en epilepsie die later in het leven ontstaat, late onset, wordt slaap-apneu gezien.

Behandeling hiervan heeft een vermindering van slaperigheidsklachten overdag tot gevolg en een verbetering van kwaliteit van leven. Tevens wordt een verbetering van de epilepsie gezien. Ook andersom geldt dat de epilepsie op zich de slaap-apneu kan doen verergeren.

\section{Aanvalsgewijze gedragingen tijdens slaap}

Bij mensen met (moeilijk te behandelen) epilepsie is het vaak niet eenvoudig om anvalsgewijze gedragingen tijdens de slaap te onderscheiden van uitingen van epilepsie. 


\begin{tabular}{|l|l|l|}
\hline Tijdstip van voorkomen in de nacht & NREM parasomnie & Nachtelijke frontale epilepsie \\
$\begin{array}{l}\text { Frequentie van voorkomen tijdens de nacht } \\
\text { Slaapstadium van voorkomen }\end{array}$ & Eerste en derde deel van de nacht & Kan voorkomen op elk tijdstip \\
Stereotypie & Diepe slaap $\left(\mathrm{N}_{3}\right)$ & Meerdere malen tot frequent \\
$\begin{array}{l}\text { Duur van de aanval } \\
\text { Herinnering van het gebeuren }\end{array}$ & Nee & Met name in lichte slaap $\left(\mathrm{N}_{2}\right)$ \\
& Tot meerdere minuten $(>\mathrm{IO})$ & Ja \\
Geen & Seconden tot enkele minuten $(<3)$ \\
\hline
\end{tabular}

Tabel 1: klinische verschillen tussen NREM parasomnie en nachtelijke frontaalkwab epilepsie.

Normale gedragingen tijdens de slaap zijn bijvoorbeeld murmelen, lachen, praten, kleine bewegingen, uitrekken, gapen of veranderen van houding. Parasomnie is een verzamelnaam van gedragingen die voorkomen tijdens de slaap, maar die niet tijdens de slaap behoren voor te komen. Parasomnieën kunnen voorkomen vanuit de diepe slaap (NREM, N3 genoemd) of vanuit de droomslaap (REM). Slaapwandelen en nachtangst bij kinderen behoren bijvoorbeeld tot de NREM parasomnieën.

Het onderscheid tussen een NREM-parasomnie en nachtelijke (met name frontale) aanvallen is niet altijd gemakkelijk (Derry et al, 2006). Daarbij komt dat NREM-parasomnieën bij een derde van de volwassenen met nachtelijke frontale epilepsie voorkomen. Bij kinderen betreft dit de helft. In beide gevallen betreft het veelal motorisch onrustige verschijnselen en de persoon kan in beide gevallen geen herinnering aan het gebeuren hebben. In tabel I worden verschillende aspecten genoemd die bij een goede anamnese duidelijkheid kunnen verschaffen over de vraag of het hier gaat om NREM-parasomnie of (nachtelijke) frontale epilepsie. Het verrichten van een electroencefalogram (EEG) hoeft hierover geen uitsluitsel te geven, aangezien er bij nachtelijke frontale aanvallen slechts in ongeveer een derde van de gevallen afwijkingen op het EEG worden gezien (Diehl, 2017). Bij parasomnieën kunnen wel positieve aanknopingspunten worden gevonden in het EEG, zoals het optreden van een hoge amplitude hypersynchrone delta-activiteit. Dit fenomeen is echter niet specifiek voor een parasomnie en kan ook voorkomen bij mensen met andere slaapstoornissen, die geen last hebben van parasomnieën (figuur I). Ook de slaapcurve kan positieve aanknopingspunten bieden, zoals optredende 'wakker episodes' vanuit diepe slaap en fragmentatie van de diepe slaap die is verdeeld over de hele nacht (figuur 2).

Ritmische bewegingsstoornissen tijdens slaap komen veel voor bij kinderen. Dit zijn vaak typische bewegingen zoals het rollen met het hoofd, het hoofd bonken in het kussen of zelfs tegen het bed of de muur. Sommige mensen rollen

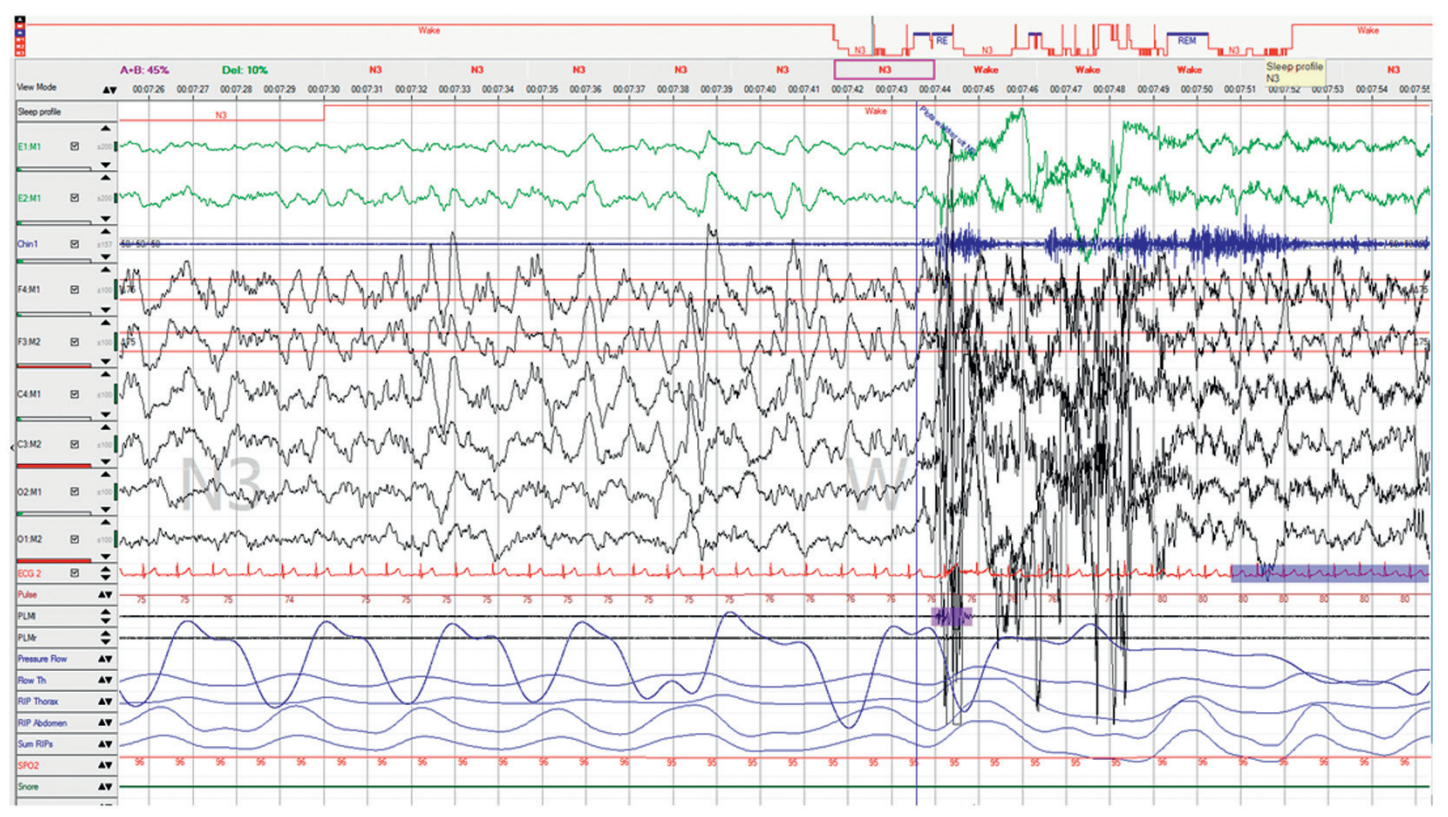

Figuur 1 Fragment van awakening uit diepe slaap op polysomnografie/EEG bij 20-jarige vrouw met klachten passend bij een NREM parasomnie (zie ook figuur 2). 


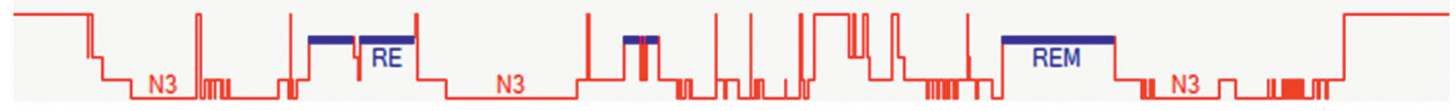

Figuur 2 Hypnogram met meerdere momenten van wakker worden uit diepe slaap en verspreiding van de diepe slaap over de gehele nacht bij 20-jarige vrouw met klachten passend bij een NREM parasomnie.

met het hele lichaam of bewegen hun handen en knieën ritmisch heen en weer. Dit wordt body rocking genoemd. Bij mensen zonder epilepsie zijn dergelijke bewegingsstoornissen wel makkelijk te herkennen, maar het moge duidelijk zijn dat dit niet eenvoudig is bij mensen, met name bij kinderen, die tijdens de slaap epileptische aanvallen hebben.

\section{Invloed van de behandeling van epilepsie}

Anti-epileptica hebben door het gunstige effect op de epilepsie, namelijk afname van de aanvallen en afname van epileptische ontladingen, een gunstig effect op de slaapkwaliteit. Nadelige affecten kunnen zijn moeheid, slaperigheid en gewichtstoename. Echter de werking van de middelen zelf heeft ook effect op de slaaparchitectuur. In onderzoek is aangetoond dat mensen die de eerste generatie middelen gebruiken (bijvoorbeeld carbamazepine, valproïnezuur, difantoïne) meer slaapstoornissen rapporteerden dan mensen die de tweede generatie middelen gebruiken (bijvoorbeeld lamotrigine, levetiracetam) (Bazil, 2003). Deze effecten zijn vaak minimaal en mogen geen reden zijn om een anti-epilepticum te staken indien er een goed behandeleffect betreffende de epilepsie bestaat. Belangrijk hierbij is op te merken dat ook het staken van anti-epileptica nadelige gevolgen kan hebben voor de slaap. Zo kan het staken van sederende anti-epileptica een afname geven van de totale slaaptijd. Het staken van anti-epileptica die tevens een stemming stabiliserende werking hebben kan een toename geven van depressieve klachten en angstklachten.

Nervus vagus stimulatie (NVS) is een niet medicamenteuze behandeling bij refractaire epilepsie, waarbij de nervus vagus zenuw wordt gestimuleerd (Romero-Osario et al, 20I8). De afgelopen jaren zijn er enige studies verricht naar het effect op de slaap. Alhoewel de onderzoeken niet allemaal eenduidig waren, bleken de klachten van slaperigheid overdag af te nemen. Verder wees polysomnografisch onderzoek uit dat tijdens gebruik van de stimulator een toename is van ademstops tijdens de slaap en dat er meer perioden van wakkermomenten (awakenings) zijn. De effecten van diepe hersenstimulatie (Deep Brain Stimulation, DBS) zijn nog onvoldoende onderzocht. Eén onderzoek liet een toename van slaapfragmentatie zien ten gevolge van een toename van wakkermomenten. Het effect van epilepsiechirurgie lijkt, op basis van de tot nu verrichte onderzoeken, een verbetering te geven van de slaapkwaliteit. Dit is het gevolg van de verbetering van de epilepsie door deze ingrepen.

\section{Wat is van belang?}

Slaapstoornissen komen veel voor bij mensen die behandeld worden voor epilepsie. Het is daarom belangrijk om bij de behandeling van mensen met epilepsie eventuele slaapklachten te herkennen en eventueel onderzoek hiernaar te (laten) verrichten. Slaap-apneu is een van de meest voorkomende slaapstoornissen bij mensen met epilepsie. Ook klachten zoals moeheid, slaperigheid overdag en psychische klachten kunnen duiden op een bijkomende slaapstoornis en hoeven niet alleen het gevolg te zijn van de epilepsie of het gebruik van anti-epileptica. Aangezien behandeling van bijkomende slaapstoornissen veelal een verbetering geeft van de aanvalscontrole en een verbetering van de kwaliteit van leven, is het van groot belang om indien mogelijk deze slaapstoornissen te behandelen.

\section{Referenties}

Bazil CW (2003) Epilepsy and sleep disturbance. Epilepsy and behavior 4: $\mathrm{S}_{39} 9 \mathrm{~S} 45$.

Derry CP, Davey M et al. (2006) Distinguishing sleep

Disorders from Seizures. Diagnosing Bumps in the night. Archives of Neurology 63:705-709.

Diehl B (2017) Frontal lobe epilepsy. Epilepsy 2017 From bench to bedside. A practical guide to epilepsy. Edited by FJ Rugg-Gunn and HB Stapley chapter 14 183-189. van Golde EGA, Gutter T et al. (20II) Sleep disturbances in people with epilepsy: prevalence, impact and treatment. Sleep Medicine Reviews 15: 357-368.

Gutter T, Callenbach PCM et al. (20rg) Prevalence of sleep disturbances in people with epilepsy and impact of quality of life: a survey in secondary care. Seizure: European Journal of Epilepsy 69:298-303.

Latreille V, St. Louis EK et al. (2018) Co-morbid sleep disorders and epilepsy: A narrative review and case examples. Epilepsy Research. 145:185-197.

Malow BA (2007) The interaction between sleep and epilepsy. Epilepsia. 48 (Suppl. 9):36-38.

Romero-Osorioa O, Gil-Tamayop S et al. (2018) Changes in sleep patterns after vagus nerve stimulation, deep brain stimulation or epilepsy surgery: Systematic review of the literature. Seizure 56:4-8. 